My left hand, which was hanging by my side, experienced precisely the same sensation as $\mathrm{I}$ have felt in receiving a shock from a weak galvanic battery. About three minutes afterwards we heard a peal of thunder, but, though we waited for some time, we neither saw nor heard anything further.

The gardener, who was one of the four, thus describes what he saw :-I thought it was a cloud of dust blowing up the avenue, and before I could think how that could be when there was not a breath of wind, I saw you three gentlemen covered for a second in a bright light, and that was all. Another of the party says that he observed what seemed to be a luminous cloud running up the avenue with a wavy motion. When it reached the party it rose off the ground and passed over the bodies of two of them, casting a sort of flash on their shoulders. The distance traversed was about twenty yards, and the time occupied between two and three seconds. (My own estimate of distance and velocity makes the time occupied almost exactly two seconds.) The day had been extremely hot and sultry, as also had the preceding day been, the thermometer readings being sometimes $80^{\circ} \mathrm{F}$. in the shade.

On asking the gardener for further particulars, he tells me that the distance traversed by the luminous cloud was about forty yards, and that, when it had gone about half the distance, he saw a flash of lightning in the direction of it, but sideways; also that the top of the cloud seemed to be three or four feet from the ground, and it gradually rose higher as it came along. When the cloud reached the party he saw one of them distinctly by its light, the night being otherwise quite dark at the time; and, lastly, that the cloud went a few yards beyond the party into the open space in front of the house, and then disappeared.

Marchfield, Davidson's Mains, Midlothian J. B. A. WATT

\section{Our Ancestors}

DURING eight centuries-say to the time of the Norman conquest-one's direct ancestors amount to a far greater number than would at first be contemplated. Taking three generations to a century, one has father and mother (2), grandparents (4), great-grandparents (8). At the end of the second century the number of ancestors springs to 64 . Following the calculation you will find that at the end of eight centuries one is descended from no less than $16,000,000$ ancestors. Intermarriage of course would reduce this estimate, and there is no doubt it must have largely prevailed. But the figures are so enormous that, in spite of all, I venture to suggest that the words "All ye are brethren" are literally true.

\section{CO-ORDINATION OF THE SCIENTIFIC} BUREAUS OF THE U.S. GOVERNMENT

A MOVEMENT is on foot in the United States for A rearranging the various scientific departments of the Government under one central authority, and a report on the subject has been made by a committee of the National Academy of Sciences, consisting of Gen. Meigs, and Professors Trowbridge, Pickering, Young, Walker, and Langley, appointed for the purpose. The Report is published at length in Science. After referring to the state of things in Europe in this respect, it gives a brief account of the method in which such bureaus are organised in other countries; discusses at some length the character of the work done by the coast and geodetic and the geological surveys, especially in those points where their provinces are similar, pointing out that two distinct and independent trigonometric surveys of the United States are now in process of execution; distinguishes between the military and meteorological work of the Signal Service, and recommends their complete separation ; indicates the danger of duplication of work by the Coast Survey and Hydrographic Office, but is not prepared to recommend that the latter be detached in any way from the control of the Navy Department, nor that the hydrographic work of the Coast Survey, for over forty years conducted so satisfactorily, be separated from that organisation, but suggests the lines on which it thinks the Coast Survey should work; lays down the principle that the Government should not undertake any work which can be equally well done by the enterprise of individual investigators, and that such work should be confined to what will "promote the general welfare of the country;" urges the importance of a proper extension of the trigonometrical survey of the United States; and. finally, recommends either the establishment of a department of science, or of a mixed commission of nine members-two of them scientific civilians to be appointed by the president for six years, two scientific men from the army and navy, three heads of the principal scientific bureaus, together with the president of the National Academy, and the secretary of the Smithsonian Institution.

To the Department of Science, or to the supervision of this Commission, it would transfer the Coast Survey, the Geological Survey, and the Meteorological Bureau, and establishing a physical laboratory, add to it a Bureau of Weights and Measures, the functions of which are now performed by the Coast Survey. The province of the proposed Commission is amply defined.

In the course of the Report the Committee give an interesting sketch of the work accomplished by the Coast Survey.

The Coast Survey was originally organised for the purpose of constructing maps and charts of the coast and harbours for the benefit of commerce and navigation. Conflicting opinions respecting the proper management of the Survey led to the formation, in 1843, of a board of officers with the duty of reorganising the Survey. This board submitted a plan which was enacted by Congress into law, upon and under which law the Survey has hitherto been executed. This plan provided for the cooperation of military officers, naval officers, and civilians in the various parts of the work. Under it the work of the Coast Survey has been continued to the present time.

In recent times a great extension of the field of operations of the Survey has been made, apparently looking to a triangulation covering the entire territory of the United States. The maps published annually with the report of the Survey enable us to know the geodetic work it has executed. It appears, from the maps accompanying the report of I882, that on June 30 of that year a chain of triangles had been extended throughout the entire length of the Atlantic and Gulf coasts, and throughout about half the Pacific coast. Besides these coast-lines, extensive regions in the interior are seen to be triangulated. In the north-east, the triangulation covers the greater part of the States of New Hampshire, Vermont, and Massachusetts, about half of Connecticut, and it also includes a considerable part of the State of New York.

The reconnaissance has extended westward from the New Jersey coast, so as to include the greater part of the State of New Jersey, and a long strip in Pennsylvania. From Pennsylvania, the extended line of primary triangulation follows the Alleghany Mountains into Northern Alabama, and is now being continued across the country to Memphis.

A triangulation of the Mississippi River was extended from its mouth nearly to Memphis, where it would meet the last-described chain of triangles. The chain connecting the Atlantic and Pacific coasts has been completed nearly across the State of Nevada, and the reconnaissance includes nearly half of Utah Territory. The line is also surveyed at various points in Colorado, Kansas, Missouri, and Illinois. Besides all this, isolated regions in Wisconsin, Indiana, Illinois, Ohio, Kentucky, and Tennessee have been reconnoitred by the Coast and Geodetic Survey, in a way indicative of a plan designed ultimately to cover the entire territory. As its appropriations for some years past have made provision for the collection of data for a general map of the United States, we may fairly regard 
the Coast and Geodetic Survey as having undertaken a trigonometric survey of the whole United States.

The general views of the Committee respecting the working of the departments of the Government are worthy of special attention. They conceive it to be a sound principle that Congress should not undertake any work which can be equally well done by the enterprise of individual investigators. The leading universities are constantly increasing the means of scientific rescarch by their professors and students; and, while the Covernment may with propriety encourage and cooperate with them, there is no reason why it should compete with them. The scientific work of the Government ought not, therefore, to be such as can be undertaken by individuals. It should also be confined to the increase and systematisation of knowledge tending "to promote the general welfare " of the country. Within these two restrictions there is a large and increasing field, which is only partly occupied by the organisations now under consideration.

The attention of Congress should be directed to the fact that the administration of a scientific bureau or department involves greater difficulties than that of a purely business department. The connections between the work done and the results ultimately to be attained for the public are not at all obrious to the people and press, and thus the great benefit of vigilant watching and constant criticism is wanting. Again : its administration requires a combination of scientific knowledge with administrative ability, which is more difficult to command than either of these qualities separatcly. These difficulties are intensified by the absence of any central authority to control the work of a Government scientific organisation. Each head of a scientific orsanisation is now practically absolutely independent, and, in his individual judgment of what his organisation shall do, is controlled only by Congress itself, acting only through its annual appropriation bills. The Committce conceive that this state of things calls for measures of reform.

A feature of such reform will be the collection of the organisations now under consideration, together with such other scientific bureaus as Congress may see fit to include in the scheme, under one central authority, to be recognised as responsible for, and controlling generally, the scientific operations of the Government. Various forms of such an authority might be devised, the choice of which will some day be made by Congress. The best form would be, in the opinion of the Committee, perhaps, the establishment of a "department of science," the head of which should be an administrator familiar with scientific affairs, but not necessarily an investigator in any special branch.

"Your Committee," the Report concludes, "states only the general sentiment and wish of men of science, when it says that its members believe the time is near when the country will demand the institution of a branch of the executive government devoted especially to the direction and control of all the purely scientific work of the Grovernment. In this day the pursuit of science itself is, visibly to all men of education, directly connected with the promotion of the general welfare.

"Should such a department be now impracticable, should public opinion not be now ready for it, the next best measure, in the opinion of scientific men, would be to transfer all such work or bureaus to some one executive department. Keeping in mind what has been said respecting the two classes of work under the Signal Service, we are of opinion that the functions of the several organisations under consideration could now be most advantageously divided among perhaps four bureaus, viz. :-

"I. The Coast and Interior Survey, to be concerned principally with geodesy and hydrography, and to consist of the present Coast and Geodetic Survey.

"2. The Geological Survey, to comprise the present Geological Survey with its organisation unchanged.
" 3 The Meteorological Bureall, to which should be transferred so much of the present personnel and functions of the chief signal office as are not necessary to the military duties of that office.

"4. A physical observatory, to investigate the laws of solar and terrestrial radiation, and their application to meteorology, with such other investigations in exact science as the Government might assign to it. In this connection, attention is called to a resolution passed by the recent Electrical Conference in Philadelphia, requesting the establishment, by the Government, of a Bureau of Electrical Standards. We are of opinion that the functions of the Bureau of Weights and Measures, now performed by the Coast Survey, could be advantageously transferred to the proposed bureat, and extended so as to include electrical measures.

"The members of your committee are conscious that placing these bureaus mnder one department would not necessarily result in the proper co-ordination of their work, because the head of such department would probably find it impracticable to enter into the consideration of all details necessary to that purpose. It appears to us that the evils already pointed out require, in any case, the organisation of a permanent Commission to prescribe a general policy for each of these bureaus. The functions of this Commission would be :-

"I. To examine, improve, and approve the plans of work proposed by the several bureaus, and to revise their estimates in accordance with such plan. The performance of this duty would require consultation with their chiefs generally and scparately respecting the character of their work, and they should be members of the Commission.

" 2 . To approve in detail the methods of expenditure of the appropriations.

"3. To recommend such measures as they deem necessary to the efficiency of the bureaus under their supervision. It should, however, be understood that this Commission is not charged with purely administrative responsibility. It prescribes what shall be done, and recommends any measures necessary to secure that object, but does not concern itself with administrative details.

"We submit the following as a suggestion for the formation and personnel of such a Commission :-

"The Commission shall consist of (I) the President of the National Academy of Sciences ; (2) the Secretary of the Smithsonian Institution; (3) and (4) two civilians of high scientific reputation, not otherwise in the Government service, to be appointed by the President of the United States for the term of six years; (5) one officer of the Corps of Engineers of the army ; $(6)$ one Professor of Mathematics in the navy, skilled in astronomy--these two to be designated by the President of the United States for a term of six years-who, with $(7)$ the Superintendent of the Coast and Geodetic Survey; (8) the Director of the Geological Survey; and (9) the officer in charge of the Meteorological Service; shall constitute the Commission of - - The Secretary of the department shall be ex officio President of the Commission.

"The members of the Commission, for their services as such, shall each be paid by the United States compensation in the sum of - dollars per annum. Their necessary transportation and travelling expenses shall be provided for as are those of the officers of the army and navy when travelling on public business or duty, to be paid out of the appropriations for the services under their supervision.

"The Commission shall meet in Washington, D.C., for the transaction of business, not less than four times a year; but the President of the Commission may convene it whenever in his judgment the exigencies of the service require a meeting. 
"The Commission shall be attached to the office of the secretary of the department of - - and under his superintendence shall exercise a general control over the plans of work of the Coast and Geodetic Survey, the Geological Survey, and the Meteorological Service, and shall have the charge and custody of all the archives, books, documents, drawings, models, returns, apparatus, instruments, and all other things appertaining to the Commission.

"The estimates of the heads of these bureaus or offices shall pass through the Commission for revision and approval; and, after the annual appropriations have been made, no money shall be expended under them, except after revision and approval by the Commission of projects submitted by these bureaus in compliance with such projects.

"If at any time public money is being spent by any of these bureaus not in accordance with the views of the Commission, the Commission shall notify the proper auditor of the fact."

Our readers are already aware that the Congressional Committee appointed to consider the organisation of the surveys and other scientific work of the Government made no report at the last Session of Congress. The Commission was, however, continued as a Commission of the succeeding Congress. The expired places of Messrs. Pendleton and Lyman were filled by. new appointments from the members elected to the next Congress. A meeting of the reorganised body has been held, which adjourned until next November without coming to any definite conclusion respecting the measures to be finally proposed. Before adjourning, Major Powell was authorised to make public the testimony which he had laid before them on different occasions, and which covers most of the points to be acted on by the Commission.

Major Powell's statements naturally include a very detailed account of the methods, work, organisation, and expenses of the Survey over which he presides. He also submitted his views upon the best method of consolidating the geological and coast surveys with the other scientific bureaus of the Government. This is the really important question before the Commission, since upon its decision must turn the general efficiency of the Government scientific service for a long time to come. The necessity for some such consolidation is strongly felt in Congress as well as outside of it. The one danger to be avoided is that of some hasty plan being adopted which may suit the exigencies of the moment, but may not work well after those exigencies have passed.

One very strong reason for placing the scientific bureaus under one head, or in one department, is that scientific work has many features peculiar to itself, which require it to be conducted upon principles different in some respects from those which prevail in other departments. The head of an ordinary bureau or department of the government, and indeed every man in public life, is conversant only with offices and duties which there is no serious difficulty in satisfactorily filling, with the aid of that knowledge of men and of the world which he acquires through his daily intercourse with others. Such a person is accustomed to finding scores of candidates for every office, from whom a suitable selectionis always possible. The idea of an office for which there may be no applicants, or, if there are any, for which it is morally certain that the applicants are all unfitted, no matter how good their recommendations, is one which he finds it difficult to assimilate. Indeed, in the case of the purely scientific office, the ability to find the proper men must be a part of the life education of the man who is to make the selection. It is safe to say that the best officers who have served in the coast and geological surveys are men who, under the ordinary system of Government appointments, would never have been heard of in connection with the positions which they so ably fill.

The same thing is true of the administration of a scientific bureau. No uniform system can be devised which will apply to all the details of a great scientific work. When we go beyond the regular routine operations it is needful that the duties shall be accommodated to the man, and that in many cases a larger measure of liberty shall be allowed the latter than could be tolerated in the usual operations of a Government department. All this requires, on the part of the administrative head of the department, an appreciation of the subject which can only be acquired by long familiarity. If the head is not specially charged with mastering the peculiar methods of administration thus rendered necessary, the chances are that he will fall into one of two opposite errors: either he will leave the heads of the scientific bureaus to manage things in their own way, without any administrative control whatever, or he will exert his authority in such a way as to endanger the efficiency of the work. The former is undoubtedly the more natural course to take, and thus arise the friction and duplication of work which so seriously impair efficiency and discipline.

Yet another feature of Govermment scientific work is that it is far removed from that public criticism which is so conducive to efficiency in other branches of the service. It is difficult to conceive that such a state of things as was exhibited by the surveys of the territories ten years ago could have existed in the performance of any work with which the public were conversant. At that time we had at least two independent surveys of the territories, prosecuted by different departments of the Government and with nominally different objects, but which were practically identical in their actual work. The officers in charge were independently surveying and mapping the very same regions. At the time that Hayden's Atlas of Colorado was published, Capt. Wheeler was engaged in surveying Colorado and making maps of the territory substantially identical in their objects with those of Hayden. Both surveys were intended to cover the whole public domain.

Nothing quite so bad as this is likely to arise in the future. But there is still room for much duplication of work as well as taste through competition in getting possession of particular fields. As a general rule, the head of a department is quite ready to approve of any extension of work which any of his bureau officers may propose, and has not always time to learn that the same work is being done, or might be better done, by some other department. The annual provision which Congress has got into the habit of inserting into the appropriations for the Signal Office- - "provided that hereafter the work of no other department, bureau, or commission authorised by liw shall be duplicated by this bureau "-is not quite satisfactory: it leaves open the question whether any proposed work is "the work of any other department, bureau, or commission."

The report of the National Academy of Sciences proposes to remedy some of these evils by placing the general policy of the scientific bureaus under the control of a mixed commission, organised somewhat after the plan of the Lighthouse Board. If the bureaus are to remain separate, we see no better plan than this for securing the proper coordination of their work; but Major Powell points out certain difficulties in the way of its successful operation. His strongest objection is, that subordinate officers of various departments would have to practically control the work, thus reducing the heads of the departments to channels for transmitting instructions. If the proposed Commission were to assume any administrative control of the work, this objection would certainly be fatal. The official responsibility of the head of a department for the work of his bureaus should not be interfered with. But the report of the Academy expressly disclaims charging the Commission with any administrative responsibility. Its sole function was to prescribe the policy of the bureaus; that is, to decide what each one should do, 
and what each one should refrain from doing, the whole execution of the work decided upon being left completely in the hands of the regular authorities. We see no reason why this should be "irksome" to the heads of the departments. We also feel that Major Powell assigns undue importance to the influence of the single military officer proposed by the Academy as one of the nine members of the Commission. It is not so clear to us, as it seems to be to him, that one such officer could leaven the whole lump of the Commission with ideas of military discipline unsuitable to the conduct of a scientific bureau.

But however favourably we may view the plan of this Commission, we must hold that the consolidation of the bureaus under a single head, or in a single department, would give far more assurance of efficiency. Especially is this the case with the two national surveys. Their work now covers the same fields, and their mutual interdependence is such that they should work under a common plan. The Geological Survey requires for its proper execution certain geodetic and astronomical work, the execution of which is not within the proper province of the geologist. It is absolutelynecessary that this geodetic and astronomical work should be so planned and executed as to meet the wants of the Geological Survey, and at the same time it is the proper function of the geodetic survey. We are informed by Major Fowell that he makes use of all the coast-survey results so far as they are available, but he does not indicate what fraction of his labour is thus saved; and it goes without saying that he has no authority, directly or indirectly, to require that the coast and geodetic survey shall do anything which he may want done.

Among the suggestions made by Major Powell was one that all the scientific bureaus should be placed under the general direction of the regents of the Smithsonian Institution. This does not appear to have been considered practicable, and was not further urged by the director himself. One of the possible plans is to place all these bureaus under the interior department. The principal objection to this course is that that department is already overloaded with work, so that its head could not give the proper consideration to the subject. Yet this is the simplest course, and would certainly be an improvement on the present state of things. The more effective course would be to form a separate department of science and public works. To this there seems to be no positive and serious obstacle except the difficulty of getting any measure of the sort enacted into a law. The question whether the head of the department should be a scientific expert or a public administrator is an ulterior one, which need not be discussed at present. In the latter case the question of its being regarded as a cabinet office would arise. There will be little hesitation in deciding this question in the negative.

\section{THE LICK OBSERVATORY ${ }^{1}$}

$\mathrm{T}$ HE Lick Observatory, in its present condition on the summit of Mount Hamilton, California, is so nearly completed, with the exception of the great telescope, that the institution may now be sketched to advantage in its permanent form. In an early issue of Science, therefore, this enterprise will be traced through its various stages, from the inception onward. Astronomers have been slow to avail themselves of the great advantages of mountain elevation and isolation in the prosecution of astronomical research, partly because of the pecuniary outlay attending the necessary expeditions, but chiefly because some of the earlier expeditions to mountain summits were not attended with results of especial importance, and, on good theoretical grounds, the meteorological conditions of such stations appeared likely to be so unfavourable as to counterbalance fully the advantages to be derived from mere elevation.
And besides, the evidence derived from the two most famous expeditions-that of Prof. C. Piazzi Smythe to the Peak of Teneriffe and of Mr. William Lassell to Maltawas so contradictory in character as to afford very good ground for abandoning the hope of immediate advantage to astronomy from superior elevations.

It is not possible to say how far Mr. James Lick was acquainted with these endeavours of scientific men; nor need the immediate circumstances or events which impelled him to his extraordinary astronomical bequest be considered here. Prof. Newcomb points out the fact that his movement followed close upon the completion of the great Washington telescope in I873, then the largest in existence. Had Mr. Lick known the opinions of the best astronomers on the subject of mountain observatories, and the likelihood of securing, on elevated and isolated peaks, results at all commensurate with the trouble and expense of occupying such stations, he would have found very little to encourage the project. In this case, however, as very often before, a little experience has proved to be worth more than an indefinite amount of scientific theorising. It has been said that the scheme of building "a powerful telescope, superior to and more powerful than any yet made," was the nearest of all to the heart of Mr. Lick: there is abundant evidence that this is true; and it may be also true that he regarded the Observatory as an appendage of the telescope. But the course of subsequent events has proved it a matter for sincere gratulation in astronomical circles that he ever regarded either the Observatory or the telescope at all; for, had not the prospective researches with the great telescope arrested his attention, there is very little reason for believing that, in so far as he was concerned, astronomical science would ever have been in a position to reap benefit from the splendidly equipped Observatory which already exists on the summit of Mount Hamilton.

That Mr. Lick was bound, heart and soul, in the project, not only of a great telescope, but of the best possible location for it, is evident from the fact that, when nearing his eightieth year, and although oppressed with physical infirmity, he resolutely undertook a waggon journey of some forty miles or more, reclining on a mattress, all for the sake of investigating a proposed mountain site in person. His solicitous concern for the enterprise was very marked. Those who knew him best say that, if his practical knowledge of astronomy had been greater, he would have given every penny of his vast fortune for the great telescope, and the Observatory and its endowment. He would have recognised, too, the great improbability of such an institution being completed within a period of a few short years, and would thus have been led to provide for the reasonable use of the instrumental equipment as fast as it was put in place on the mountain. The failure to make such provision constitutes the chief point of unfavourable criticism on the part of astronomers, and is in many respects unfortunate; but sundry advantages also have arisen from it, which may be recognised with more profit, particularly as this condition of things must remain unalterable until the great telescope is completed, and the entire institution comes under the administration of the University of California, in full accord with the terms of Mr. Lick's bequest.

Five years ago no one could have anticipated that the year I886 must pass with the great telescope still unfinished. It is worthy of note, however, that, while the delay in obtaining the necessary glass for the objective has proved so great an embarrassment to the work of the opticians, it has not as yet sensibly impeded the progress of the construction of the Observatory itself. 'To this fact we alluded at p. 377 of the current volume of Science, stating as well the very reasonable grounds for the belief that the plans of the Lick trustees, in so far as they pertain to the construction of the great telescope 